\title{
TECHNOLOGICAL LIGHTING FOR AGRO-INDUSTRIAL INSTALLATIONS IN RUSSIA
}

\author{
Leonid B. Prikupets \\ LLC “VNISI named after S.I. Vavilov", Moscow \\ E-mail:prikup@vnisi.ru
}

\begin{abstract}
The paper gives a review of the current state and future development of technological lighting in the main production sectors of agriculture and horticulture in Russia. Current data is given and an evaluation of the effects of lighting on livestock, poultry, fish, mushrooms, and plant productivity is carried out. The practical application of the latest innovations in lighting technology and photo biology is described.
\end{abstract}

Keywords: lighting in agriculture, photo period, high-pressure sodium lamps (HPS lamps), light emitting diodes (LED) phyto-irradiators, light culture for plants, photosynthetic photon quantities, regulatory base

\section{INTRODUCTION}

The accelerated growth of agricultural industries is one of main priorities of the Russian state. Over the last several years there has been a steady annual increase of no less than $3 \%$ due to various kinds of state support and large private investments. The de- velopment of agricultural industries is driven by innovation: new facilities for rearing livestock, poultry, fish, mushroom and plant-growing farms are under construction; new equipment and high performance technologies are applied.

Electrical lighting plays an important role in every kind of modern agriculture, and especially in greenhouse cultivation.

\section{LIVESTOCK AND POULTRY FARMS}

Favourable lighting conditions play a major part in creating the necessary microclimate which ensures a normal physiological state and high productivity of animals and poultry, as well as creating optimal conditions for staff operating the farms.

Recommended illuminance levels for livestock and poultry farms were established long ago in the former USSR, based on longitudinal agronomic studies and have not been revised in 20 years. Current norms OSN-AIC2.10.24-001-04 [1] do not differ greatly from a similar document of 1991, which was developed with assistance from VNISI.

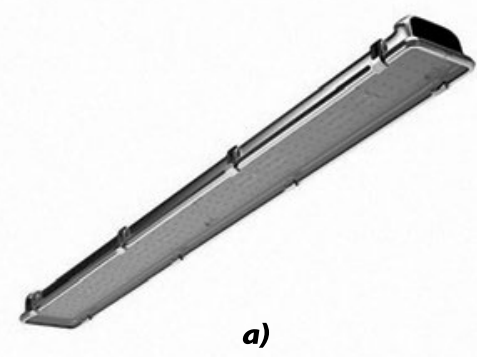

a)

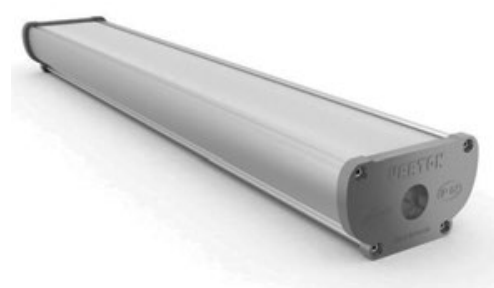

b)
Fig. 1. LED luminaires for livestock farms: a) INOX LED70("Lighting technologies”): $67 \mathrm{~W}, 7000 \mathrm{~lm}$, 5000K; [4]

б) IronAgro ("Varton"): $36 / 54 \mathrm{~W}$, 4000/6300 lm, $4000 / 6500$ K [5] 


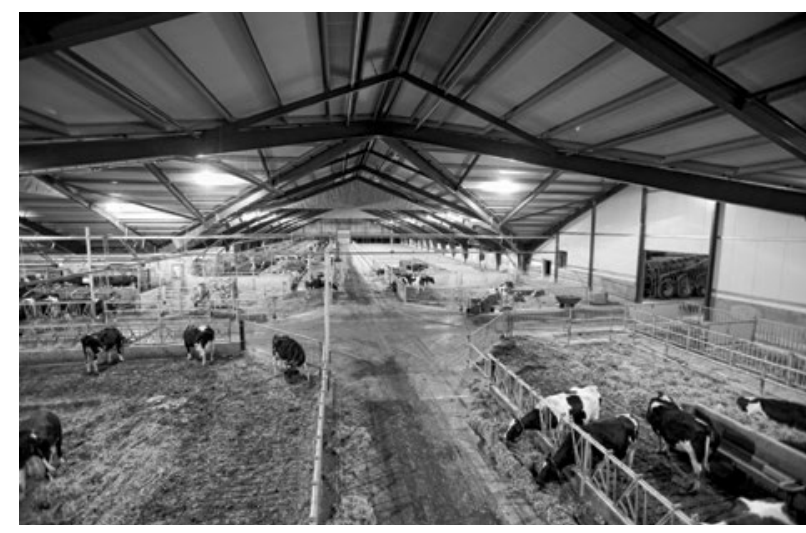

Fig. 2. LED lighting in livestock farm [6]

\subsection{Illumination of cattle farms}

The illuminance levels given in [1] relating to animals pens $(E=(20 \div 30) \mathrm{lx})$ and feeding areas $(E=(50 \div 75) \mathrm{lx})$ are obsolete and not applied. Modern farms are intensive milking facilities (for several hundred cattle) and beef farms (up to 2030 thousand cattle) equipped mostly with imported machinery. Together with the equipment, new technologies are coming to farms in Russia, including new lighting.

Studies conducted in several countries in the last 10-15 years, particularly those conducted in Germany, show that light, which is an active stimulant for many biochemical processes, affects the growth, development, wellbeing, fertility, and yield of large horned livestock.

Proper lighting enables the free movement of cows in loose range housing as well as the rational consumption of feed. According to [2,3] for the main production areas, in the drinking trough zones and feeder troughs the illuminance must be (200-300) lx, while in the pens for milking cows, it should be 200 lx. Milking cows need lighting for up to 16 hours followed by 8 hours rest during the autumn and winter period. Following these recommendations can increase the productivity of dairy cows by $8 \%$.

Obviously, the higher lighting recommendations also improve working conditions for farm personnel.

Radical changes have taken place in cattle farms with regards to the range of available light sources and luminaire products. Although the outdated standard norms still specify filament lamps, fluorescent lamps, and high-pressure mercury lamps using (710 years ago high-pressure sodium lamps were seen to be pioneering and achieved good results in farm

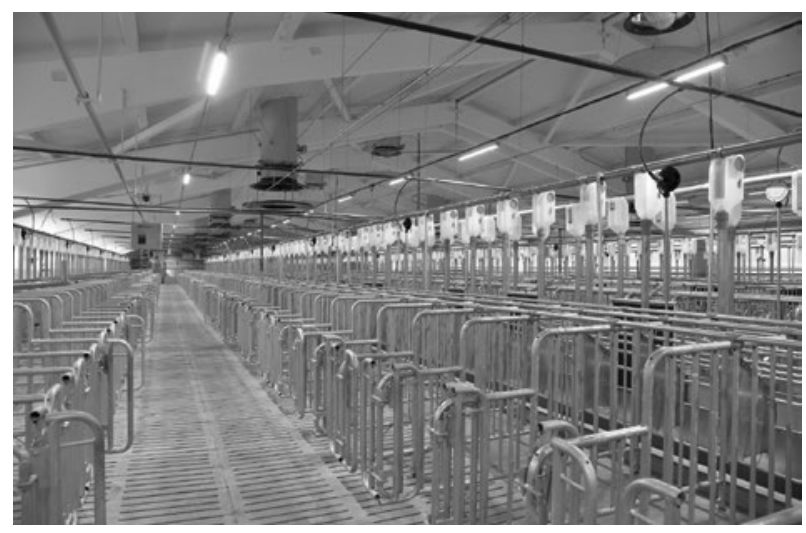

Fig. 3. LED lighting in pig-breeding complex [7]

lighting), LED luminaires have come to the forefront in the last few years. Whilst climate control systems have led to a significant reduction in the concentration of aggressive vapours (ammonium and other substances), a luminaire designed for cattle farms needs to be IP65 protected, and its housing must be manufactured from chemically resistant ABS-plastics or anodized aluminium, and its diffuser - from acryl or polystyrene.

Fig. 1 gives examples of LED luminaires used in new designs for cattle farms, and Fig. 2 shows a picture of a modern farm.

\subsection{Lighting in pig breeding farms}

The lighting level inside a modern pig breeding farm, Fig.3, varies from $50 \mathrm{~lx}$ to $100 \mathrm{~lx}$ and even to $300 \mathrm{~lx}$, and the lighting period - from 10 to 16 hours. Given the physiological needs of fattened animals, the general approach is simply to maintain a moderately lit or even darkened environment [8].

Special LED luminaires are used in new pig farms. The luminaires are water and dust-tight, resistant to an aggressive environment and can withstand high pressure water jets when the facility is washed.

It should be noted that the use of LEDs has led to a significant reduction in power consumption in the farms by up to 2 times.

\subsection{Lighting for poultry production}

A modern poultry farm is a complex of rooms isolated from the outdoor environment with a controlled microclimate, including lighting that provides good physiological conditions for poultry and enables an increase in almost all productive charac- 


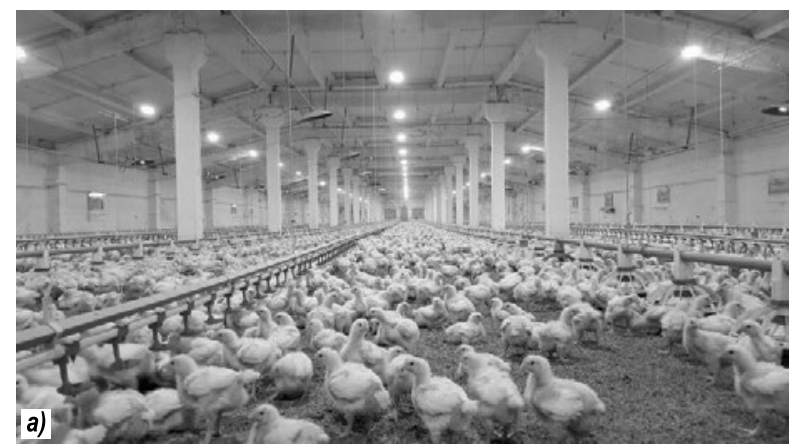

Fig. 4. LED lighting in poultry complex: a) with floor reared poultry [11]; b) with caged birds [12] teristics of poultry, an improved survival rate and decreased feed costs.

The effect of electrical lighting on poultry, the reasonable use of the "lighting factor" and its essential features are discussed in $[9,10]$.

Since poultry birds react negatively to instant on-and-off switching of lighting, there is a need to simulate natural dawn and dusk effects by using intermittent or rhythmically variable lighting. LED luminaires are best suited for this. They are quickly replacing luminaires with incandescent lamps and tubular and compact fluorescent lamps.

At present, about 200 poultry farms have been equipped with LED luminaires, and the total number of LED luminaires has reached nearly one million units. The lighting systems in the farms operate several specific scenarios with intermittent modes. The luminous flux is effectlively regulated within the range $0 \div 100 \%$ due to pulse-width modulation at a frequency exceeding $300 \mathrm{~Hz}$.

For the floor-reared broilers (Fig.4a) the recommended illuminance level is $45 \mathrm{~lx}$, while for cell-breeding of chickens (Fig.4b) the illuminance level in the feeder areas must reach 100 lx.

The luminaires for poultry farms are usually linear fixtures with the following features: rated

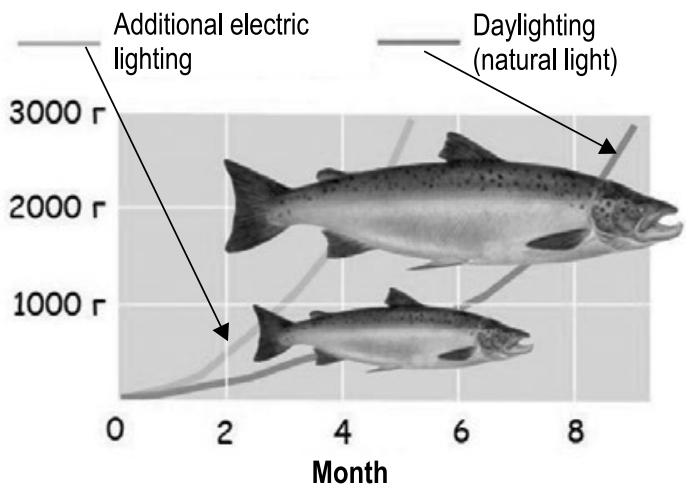

Fig. 5. Light stimulation effect in fish farming [16]

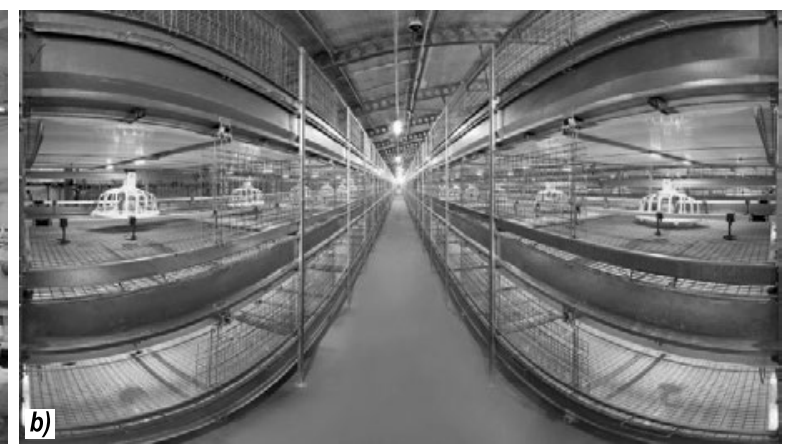

power about $(10 \div 12) \mathrm{W}$, colour temperature $T_{c}=$ $(3500 \div 5000) \mathrm{K}, R_{a}>80$. For safety reasons the luminaires are operated from the secondary power-supply units having direct output voltage of $24 \mathrm{~V}$, $36 \mathrm{~V}$, or $48 \mathrm{~V}$.

“Technosvet Group Ltd.”, the leading company in poultry farm lighting, states that the use of LEDs will reduce electricity costs by 10-12 times compared with the usage of incandescent lamps and 1.5-3 times compared with fluorescent lamps [13].

\section{LIGHTING FOR AQUACULTURE}

The term "aquaculture" refers to commercial fish farming in inland ponds or factory pools, or specially created marine plantations. First developed occurred in the 1980s in Norway as intensive production, modern day aquaculture is a platform for the application of effective knowledge-based technologies, including electrical lighting. Norwegian salmon, salmon, and sturgeon, carp and other fish species are produced in aquaculture conditions.

Ambient light is a key factor for fish rearing as it synchronizes all life stages of growth and development. Visual (photo taxis) and non-visual (circadian biorhythm) reactions controlled by spectra,

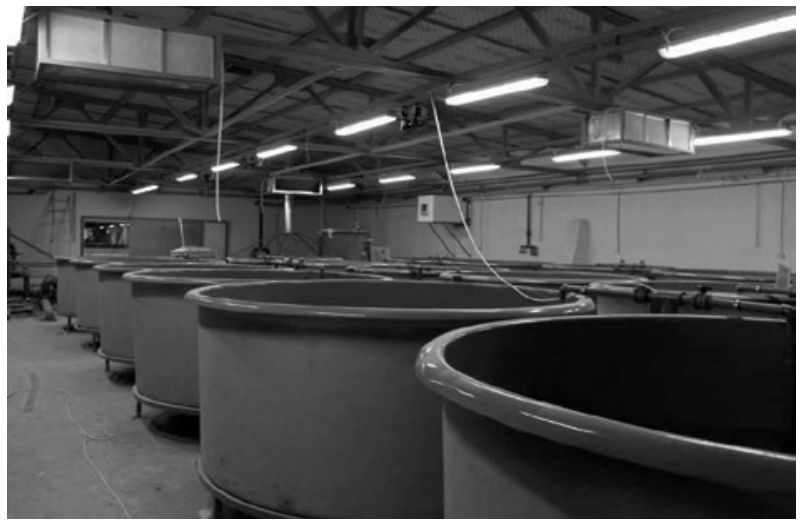

Fig. 6. Lighting in a fish farm [17] 

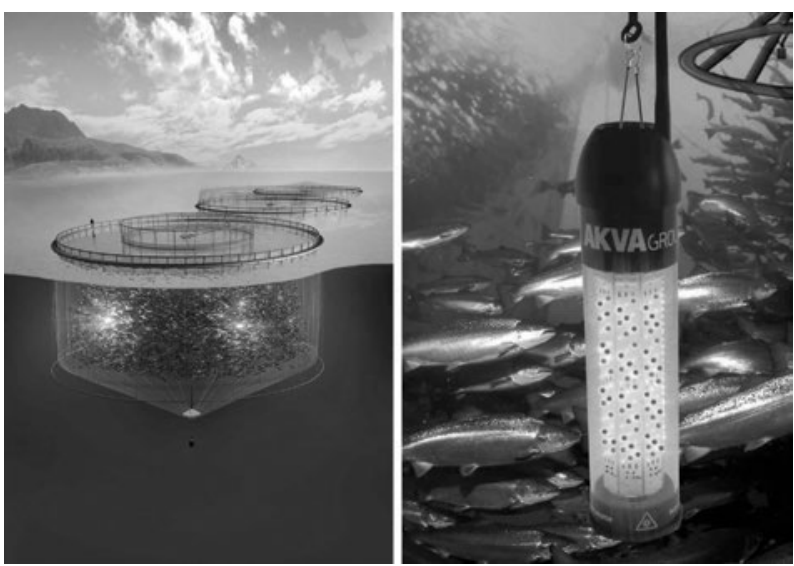

Fig. 7. Lighting in aqua farm using a submersible fixture [18]

lighting level, and photoperiod determine fish behaviour. Operating a light source over the surface of the pool (at a fish factory) or submerged (at an aqua farm) is perceived by the fish as a continuous "light day" and becomes a signal for active feeding, leading to more rapid weight gain, accelerated growth and development, improving the quality of the products $[14,15]$. As in humans, the coming of darkness dramatically increases the production of melatonin in fish and suppresses its activity. The achieved effects can be quite significant (Fig.5) which justifies makes necessary the application of special luminaires with HID or LED. At a fish factory artificial lighting is used almost all year round (Fig.6), while at aqua farms in sea cages (Fig.7) it is used mostly during months with a short light day.

Light stimulation is most effective during the early stages of fish development [15]. The following recommendations were formulated as a result of a series of studies:

- For tilapia: illumination on the surface of a pool $\mathrm{E}_{\mathrm{s}}=600 \mathrm{~lx}$, lighting duration $-\tau_{\phi}=12$ hours [19];

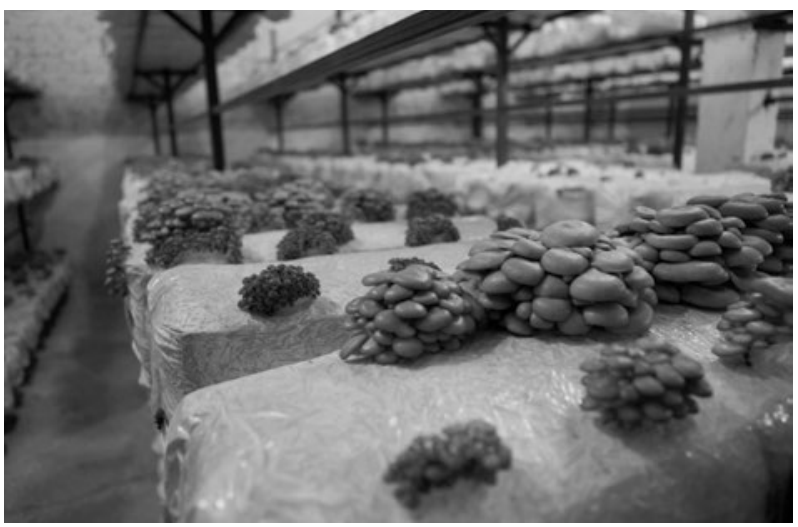

Fig. 8. Oyster mushrooms farm [24]
- For young sturgeon: $\mathrm{E}_{\mathrm{s}} \leq 800 \mathrm{~lx} ; \tau_{\phi}=12 \mathrm{~h}$, it is preferable to use a green radiator [14];

- For young carp: $\mathrm{E}_{\mathrm{s}}=20 \mathrm{~lx} ; \tau_{\phi}=20 \mathrm{~h}$ [15].

Aquaculture is one of the most attractive sectors for investments abroad. The production of farmed fish over the last 30 years has increased 12 times. Studies on the more subtle mechanisms of lighting stimulation and new technologies of growing seafood are being carried out in the USA, Norway and other countries. In Russia, aquaculture began to develop in the last 3-5 years, and the potential of using lighting in this area is significant.

\section{LIGHTING IN FUNGICULTURE}

The industrial scale growing of mushrooms in specialised indoor facilities is undergoing an active revival in Russia (by 2020 mushroom production of mushrooms should increase twelvefold compared to 2013), it is worth considering this field as of interest for lighting research and trade.

Mushrooms are a valuable source of high-quality and environmentally clean protein; hence their intense indoor cultivation. Champignons, oyster mushrooms, shiitaki and other mushrooms with an average annual yield of $300 \mathrm{~kg} / \mathrm{m}^{2}$ are being industrially grown in facilities with a strictly controlled climate $\left(t=(13 \div 20){ }^{\circ} \mathrm{C}\right.$, humidity of $(85 \div 90) \%$, low $\mathrm{CO}_{2}$ content).

Mushrooms are not phototrophic organisms, which transfer optical radiation into an organic substance (energy). Nevertheless, light is a morphogenetic factor for most kinds of mushrooms, since it provides photo-regulation of their metabolism, affecting productivity. Issues of photo-regulation in mycelium and in the growth of mushrooms are rather complex and so far have not been systematically researched, but have been studied actively in recent years [20]. It is known that chromoproteins in mushrooms serve as light sensors sensitive in the blue part of visible spectrum (flavin), and in the red part - phytochrome, which is similar to the receptors of higher plants.

It is assumed that significant effects increasing productivity could be achieved by using blue radiation with $\lambda=(430 \div 470) \mathrm{nm}$ [21].

The results of photobiological studies, including those on molecular level, find practical application in agricultural production. Special tests confirm that visible radiation (both illuminance level and duration of illumination) activates the growth 


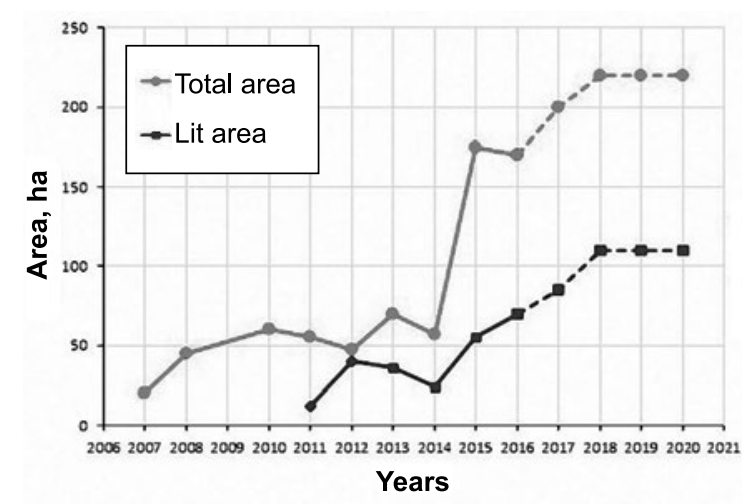

Fig. 9. Construction of new greenhouses in Russian during the last ten years and forward to 2020

processes, in particular, in oyster mushrooms, by affecting formation of bodies and productivity [22]. An illuminance level of $(150 \div 200) \mathrm{lx}$ (white light) for a photoperiod of 10-12 hours during the whole cultivation period is currently used in oyster mushrooms cultivation technology on one of the production farms (Fig.8) [23].

At the same time, it has also been demonstrated that with an increase in illuminance level up to 1000 lx for 12 hours daily lighting duration the yield of oyster mushrooms can increase by

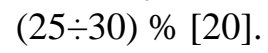

Based on an analysis of a small but relevant amount of experimental and practical data, and considering the planned scale of development, it can be concluded that there are significant opportunities for the use of artificial lighting for industrial mushrooms production, which will make an important contribution to the creation of environmentally friendly technologies for the cultivation of mushrooms, including those with a specified bio-chemical composition.

\section{LIGHTING (IRRADIATION) OF PLANTS IN GREENHOUSES}

\subsection{General context}

At present, greenhouse cultivation is one of the fastest growing agricultural industries, and perhaps in the Russian production economy overall.

At the end of 1980s in the former USSR, the total area of winter greenhouses was about 4000 ha, and from the beginning of 1990s steadily decreased: by 2010 it had dropped to 1800 ha. But due to government support and the construction of new flower and vegetable greenhouses, the total area has reached 2300 ha in 2017. By 2020 there are plans to build another 1000 ha and to double the production of greenhouse vegetables. Fig. 9 shows data on the construction of new greenhouses during the period from 2007 to 2017, and gives a forecast up to 2020.

Modern industrial greenhouses in Russia represent a small but very specific sector of the economy, both highly power consuming and energy efficient; about two dozen new technology methods are used in this sector, including the computer controlled cultivation of plants. Lighting is the most important technology in the new greenhouses since it allows the facility to grow plants almost all year round. Fig. 10 shows the distribution of areas between different kinds of plants.

The total annual electric power consumed by the greenhouses in Russia is about $650 \mathrm{MW}$, the number of light units (mostly luminaires with high-pressure sodium (HPS) lamps of 400W, 600W, and $1000 \mathrm{~W}$ ) exceeds one million pieces. Greenhouse lighting consumes about 1/8 billion $\mathrm{kW}$ per hour of electric power, which exceeds the consumption of civic lighting in the cities of Moscow, St. Petersburg, Nizhny Novgorod and Kazan.

Here are the main technical parameters for lighting technology for cultivation: a specific installed electric power range $(100 \div 250) \mathrm{W} / \mathrm{m}^{2}$ (depending on the type of plant); the duration of lighting per year is up to 5500 hours; illuminance levels are $(10 \div 30) \mathrm{klx}$; yield is up to $150 \mathrm{~kg} / \mathrm{m}^{2}$ (for example for cucumbers); the average annual energy consumption for $1 \mathrm{~kg}$ of product is up to $15 \mathrm{kWh}$.

The annual capacity of the luminaire market for greenhouses mostly depends on the amount of newly commissioned areas to be lit. In 2017 it may be up to 250-270 thousand pieces. Note that both the rate of construction of new greenhouses with artificial lighting in Russia (Fig.10) and their share

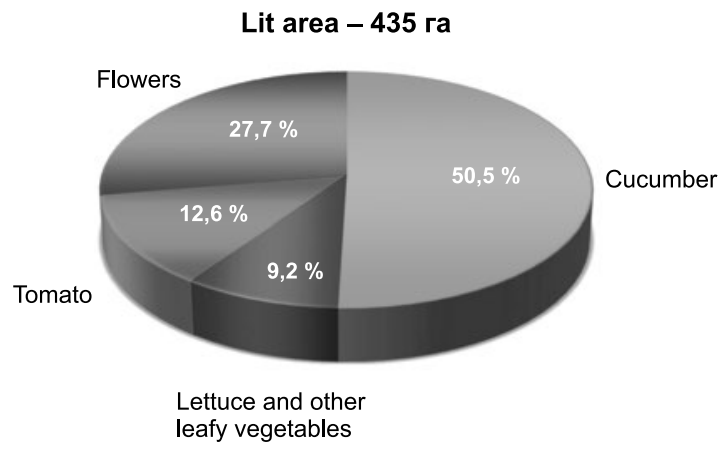

Fig. 10. Area distribution in greenhouses in Russia 
Table 1. The main parameters of HPS phyto-lamps in tubular bulbs $\left(P_{l}-\right.$ lamp wattage, $U_{m}-$ mains voltage, $I_{m}$ - current, taken from the mains, $I_{l}$ - lamp current, $U_{l}-$ lamp voltage, $P_{b}$ - power losses in the ballast, $\Phi_{l}-$ lamp luminous flux, $\eta_{v}$ - lamp efficacy, $\Phi_{P P F}-$ photosynthetic flux of photons (lamp), $\eta_{p h}$ - lamp efficiency in PAR range, $\emptyset_{l}$ - lamp bulb diameter)

\begin{tabular}{|c|c|c|c|c|c|c|c|c|c|c|c|}
\hline № & $P_{\mathrm{l}}, \mathrm{W}$ & $U_{\mathrm{m}}, \mathrm{V}$ & $I_{\mathrm{m}}, \mathrm{A}$ & $I_{\mathrm{l}}, \mathrm{A}$ & $U_{\mathrm{l}}, \mathrm{V}$ & $\begin{array}{c}P_{\mathrm{l}}+P_{\mathrm{b}}, \\
\mathrm{W}\end{array}$ & $\begin{array}{c}\Phi_{\mathrm{l}}, \\
\mathrm{klm}\end{array}$ & $\begin{array}{c}\eta_{v}, \\
\mathrm{~lm} / \mathrm{W}\end{array}$ & $\begin{array}{c}\Phi_{P P F}, \\
\mu \mathrm{mol} / \mathrm{s}\end{array}$ & $\begin{array}{c}\eta_{p h}, \mu \mathrm{mol} / \\
(\mathrm{s} \cdot \mathrm{W})\end{array}$ & $\begin{array}{c}\emptyset_{\mathrm{l}}, \\
\mathrm{mm}\end{array}$ \\
\hline 1 & $250^{*}$ & 220 & 1,5 & 3,0 & 100 & 285 & 33,2 & 132 & 420 & 1,7 & 46 \\
\hline 2 & $400^{*}$ & 220 & 2,4 & 4,4 & 104 & 445 & 56,5 & 140 & 725 & 1,8 & 46 \\
\hline 3 & 600 & 220 & $\begin{array}{c}3,4^{*} \\
2,9 * *\end{array}$ & 6,2 & 112 & $\begin{array}{c}645^{*} \\
635^{* *}\end{array}$ & 90,0 & 150 & 1100 & 1,8 & 48 \\
\hline 4 & 600 & 380 & $\begin{array}{c}1,90^{*} \\
1,61^{* *}\end{array}$ & $3,6^{*}$ & 200 & $\begin{array}{c}645^{*} \\
640^{* *}\end{array}$ & 90,0 & 150 & 1150 & 1,9 & 48 \\
\hline 5 & $1000^{* *}$ & 380 & 2,61 & 4,0 & 250 & 1040 & 145 & 145 & 2100 & 2,1 & $32 * * *$ \\
\hline
\end{tabular}

* - with electromagnetic ballast; ** - with electronic ballast; *** - in overhead installation

in the general volume of newly built greenhouses are unique in global practice.

\subsection{Light sources for greenhouses}

Almost all production greenhouses are equipped with "phyto-HPS" lamps. These lamps differ from the conventional HPS lamps by higher pressure of buffer gas that enables a raised luminous efficacy up to $150 \mathrm{~lm} / \mathrm{W}$ (for $600 \mathrm{~W}$ lamps), an increased lifetime and stability of luminous flux, and a slight increase in the fraction of radiation in important for growth and development of plants blue range of photosynthetically active radiation (PAR). The main parameters of phyto-HPS in tubular bulbs are given in the Table 1 .

Although the spectrum of an HPS is not considered to be the most favourable for the growth and development of plants, these lamps combined with advanced cultivation techniques have provided high levels of plant productivity. The greenhouses environment is a good example of the combined action of daylight and artificial lighting, therefore, even during the low light time of year (e.g. December), when the share of light provided by artificial lighting is up to $90 \%$, daylight still makes a significant addition to the total spectrum in the blue part of the PAR, providing the necessary photo-regulation for the plants.

The Russian agricultural sector uses phyto-HPS lamps from leading foreign manufacturers: $B L V$ (Germany), Osram (Germany), Philips (the Neth- erlands), Narva (Germany), MegaPhoton (China). Not the full range of HPS lamps is produced in Russia. "Reflax Ltd." is the largest and most well-known Russian manufacturer of HPS lamps with mirror and tubular bulbs and import discharge tubes. "Lisma" also started to produce tubular phyto-lamps. "BL-Trade Ltd." has organised the production of the most popular types of $600 \mathrm{~W}$ and $1000 \mathrm{~W}$ phyto-HPS lamps at a foreign factory under the brand name "Galad".

\subsection{Luminaires for greenhouses}

The luminaires (phyto-irradiators) for greenhouses must have high functionality and operational characteristics. Only luminaires with an efficacy of $(120 \div 125) \mathrm{lm} / \mathrm{W}$ (for $600 \mathrm{~W}$ fixtures) can successfully compete in the market with foreign manufacturers. This means that the light output ratio of a reflector should be at $(90 \div 92) \%$, active power losses in the ballast must be minimal $(7.0 \div 7.5) \%$ (for $600 \mathrm{~W}$ fixtures), the luminaire must be durable and long-lasting, with a low weight and an acceptable price.

"Reflux" reflector lamps (lamps-luminaires) have the key part of the luminaire design, i.e. reflector. Due to the use of silver instead of aluminium for the reflective layer, the products have an increased efficiency and are widely used in new greenhouses.

Luminaires, both with electromagnetic (for 250, 400 , and 600W) and electronic (for 250, 600, and $1000 \mathrm{~W}$ ) ballasts, are currently available on the mar- 


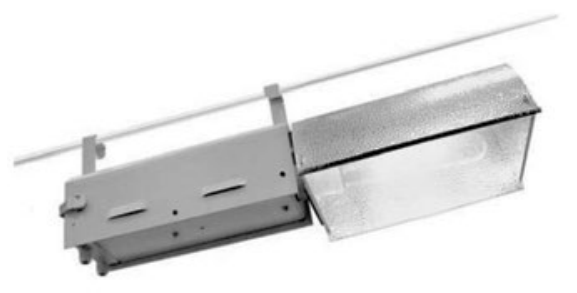

a)

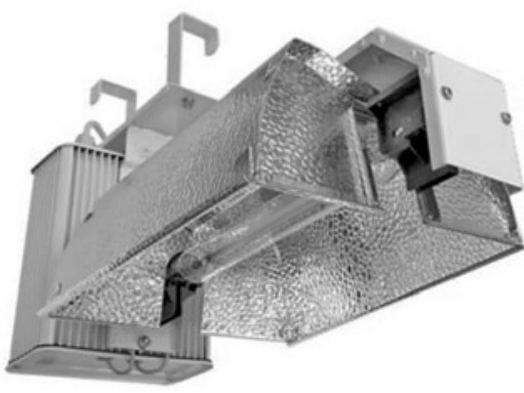

b)

Fig. 11. Galad greenhouse luminaires [26]: a) JSP30-600-013; б) JSP38-1000-003

ket. The type of ballast determines the faults and benefits of a phyto-irradiator; this is well understood and discussed in detail, e.g. in [25]. Luminaires with electronic ballasts have a low weight and are capable of adjusting the electrical power of a lamp, but they are less reliable and more expensive. On the contrary, luminaires with electromagnetic ballasts are more reliable and less expensive, but heavy. Examples of the most popular HPS luminaires on the market with wattages of $600 \mathrm{~W}$ and $1000 \mathrm{~W}$ are given in Fig.11. At least for the current year, the preferences of consumers who are building new greenhouses are distributed equally between two choices.

Hortilux (the Netherlands) and Gavita (the Netherlands - the USA - Canada - Norway) are well known and established on the Russian market for greenhouse luminaires. They are in competition with other products by a company with a 45 year history in the production of phyto-irradiators from Kadoshkino (under trade-mark "GALAD”) and also by "NFL", "Tochka Opory", and "Reflux Ltd”.

\subsection{Lighting installations for modern greenhouses}

Lighting installations (LI) in greenhouses are cannot be compared to other lighting systems due to their power consumption (more than 2000 luminaires with a rated wattage of $600 \mathrm{~W}$ are installed per hectare), which is more than an order of magnitude greater than in other high power consumption lighting systems, e.g. sports lighting. Special measures are being taken to improve the utilisation factor of luminous flux (reaching a level of $0.95 \div 0.97)$ through the use mirror screens on the ceiling and walls at night time, not only for maximising efficiency but also for the reduction of light pollution in the outside environment.
During lighting design a priority is given to obtaining the optimal ratio between the illuminance level $E$ and the specific installed electric power $P_{1}$ : $K_{L I}=E / P_{1}$, which is an indicator of lighting efficiency. Usually, it is at the level of $K_{L I}=(125 \div 130)$ $\mathrm{lm} / \mathrm{W}$.

The illuminance must be stable, though there will be some decrease due to a reducing luminous flux of lamps. Our measurements have found that the the reduction in luminous flux for HPS lamps is about $(18 \div 20) \%$ after four years of operation; the calculations take into account the direct dependence of productivity on the illuminance level give grounds to conclude that using lamps further after four years is economically unreasonable [27].

\subsection{LED phyto-irradiators for greenhouses}

Radical changes in the market for greenhouse lighting have taken place with the rapid development of light-emitting diodes (LEDs) and the replacement of conventional HPS lamp fixtures by LED luminaires. Having reached and exceeded the efficiency level of sodium phyto-irradiators, LED-irradiators also surpassed them by tuning spectral characteristics to match the specific needs of crops and cultivation.

Regretfully, many developers and manufacturers trying to win time and stay ahead of competitors, neglect long and expensive photobiological studies needed to optimise the design requirements for phyto-irradiators. Instead they invent various quasi-scientific approaches in an effort to "fit" the actual spectrum of radiation to the photosynthesis sensitivity spectrum, although it is well known that there is no unified optimum spectrum for all plants.

VNISI takes a different approach, attempting to solve this problem in cooperation with plants physiologists, based photobiological studies and re- 


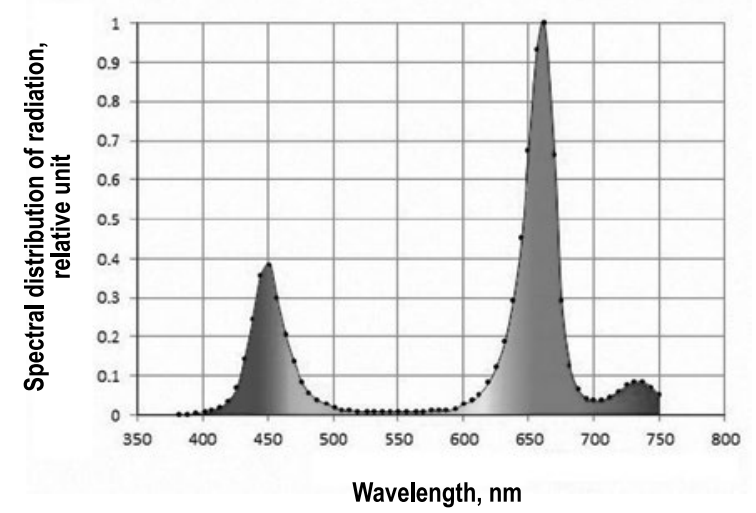

a)

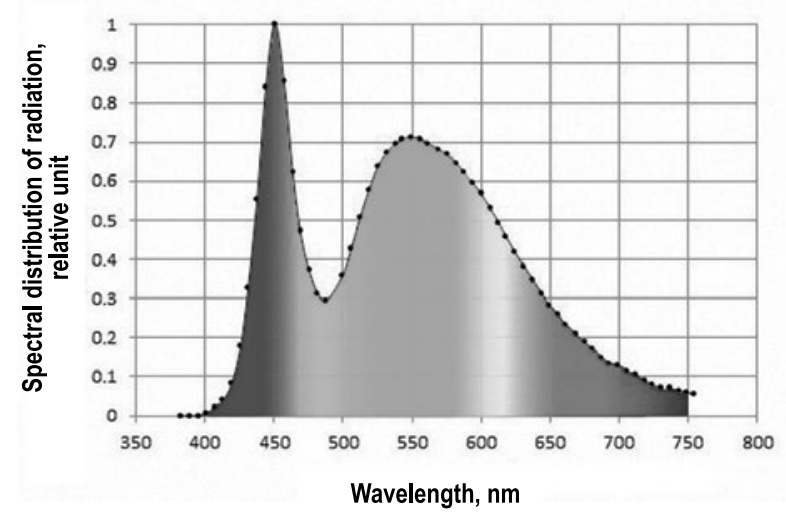

b)

Fig. 12. Typical spectra of LED-irradiators: a) “doublepeak" irradiator; б) "white” irradiator

sults which can be applicable in greenhouses [2831]. Such optimisation could yield energy savings of $(30 \div 35) \%$ if HPS lamps were replaced by LED-irradiators [28, 29].

Currently, the supply of LED-irradiators on the Russian market greatly exceeds demand. Nearly two dozen foreign and domestic companies offer their products. The irradiators comprise LEDs based on either AlGaInP or InGaN structures that generate red and blue radiation, or InGaN structure together with a phosphor that generate full spectrum light. The LED arrays are packed either by SMD or $C O B$ technologies. The LEDs are produced by the leading foreign manufacturers: Cree (the USA), Osram Semiconductor (Germany), Lumileds Luxeon (the USA), Nichia and Citizen (Japan), etc. Fig. 12 shows spectra of radiation used in greenhouses: Fig.12a shows the "double-peak" spectrum of a red-blue irradiator, and Fig.12b shows the spectrum of a "white" irradiator with correlated colour temperature in the range of $1800 \mathrm{~K}$ to $6000 \mathrm{~K}$.

LED phyto-irradiators are introduced into greenhouses in the following forms:

- Traditional overhead lighting;

- Inter-row lighting;

- Multi-tiered systems for growing plants.

Overhead irradiators are designed to replace HPS luminaires, they may be of rectangular or linear shape, with a wattage from $100 \mathrm{~W}$ to $600 \mathrm{~W}$. Inter-row LED-irradiators are of $(35 \div 160) \mathrm{W}$, $(0.85 \div 2.50) \mathrm{m}$ long with a specific power of $(0.4 \div 0.65) \mathrm{W} / \mathrm{cm}$ (Fig. 13). The LED-irradiator for multi-tiered systems have no alternative, hence their volume of production depend only on the rate of market uptake of innovative phyto-installations like “City-Farm” (Fig. 14).
The main reason for the slow penetration of all kinds of LED-irradiators on the greenhouse market is their high cost. Detailed technical and cost analysis shows that the payback period for introducing LED-irradiators is no less than 5-7 years [35]. However, it should be noted that in 2017 the first large project based on LED-irradiators will be realised in one of the Russian greenhouse complexes [36].

\subsection{New problems in measuring photosynthetically active radiation (PAR)}

The use of LED-irradiators with different spectra (including radiation at the borders of the visible range) made it necessary to introduce a new system for PAR measurement. In the 1960s it a new system was proposed which would account for both the number of photons in the PAR range $(\lambda=(400 \div 700)$ $\mathrm{nm})$ absorbed by the plant and the equivalent number of $\mathrm{CO}_{2}$ molecules resulted due to photosynthesis [37]. Thus, by using recommendations of

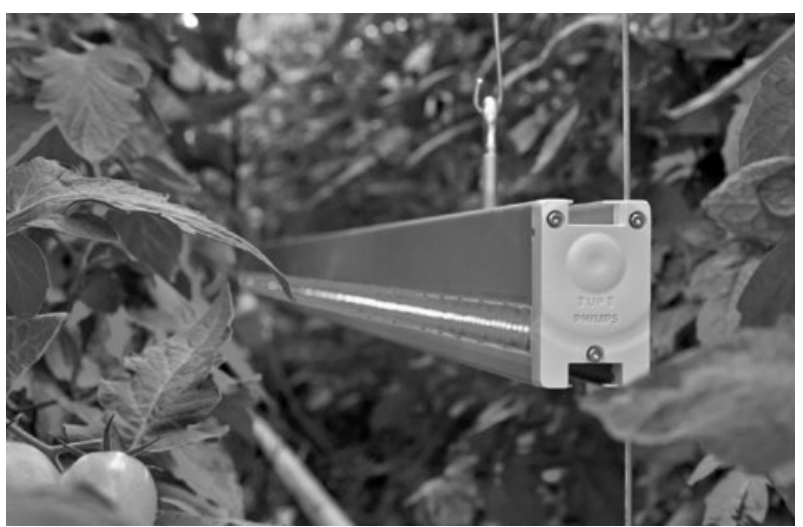

Fig. 13. Inter-row lighting system with Philips LEDirradiators [32] 


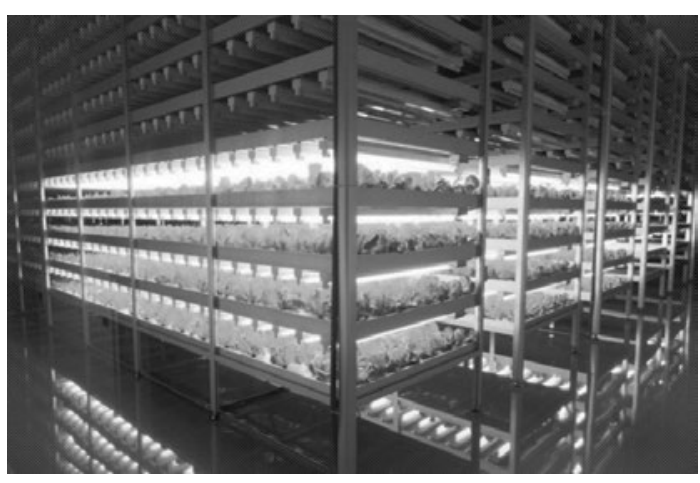

a)

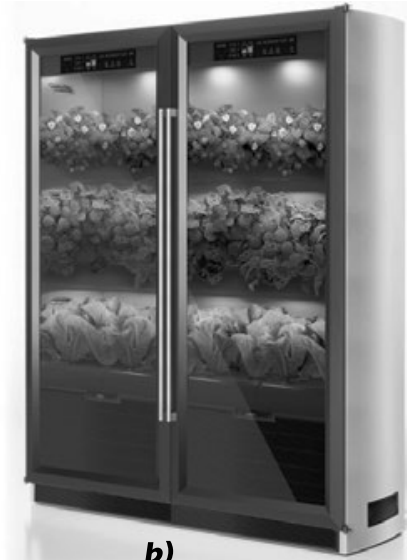

b)

Fig. 14. Multi-stack installation for growing plants with LED irradiation: a) industrial, "CityFarm” type [33]; b) home-scale [34]

DIN5031, t.1,1985 [38] and for practical convenience, the ratio of the quantity of photons to the Avogadro number, the unit for measuring photosynthetic photon flux $\left(\Phi_{P P F}\right)$ in $\mu \mathrm{mol} / \mathrm{s}$ was introduced, as well as its derivatives: $E_{P P F D}$ density in $\mu \mathrm{mol} /$ $\left(\mathrm{m}^{2} \cdot \mathrm{s}\right)$, and $\eta_{P P F}$ efficacy in $\mu \mathrm{mol} /(\mathrm{s} \cdot \mathrm{W})$ or $(\mu \mathrm{mol} / \mathrm{J})$, etc. Several photon values for HPS lamps are given in Table 1.

The photosynthetic photon flux as an effective value may be written in the following canonical form:

$$
\Phi_{P P F}=\int_{400}^{700} \Phi_{e}(\lambda) \cdot S(\lambda) d \lambda,
$$

where $S(\lambda)=\frac{\lambda}{h \cdot c \cdot N_{A}}$ is a function of spectral efficiency within photosynthetic photon system of variables, $\Phi_{e}(\lambda)$ is a spectral density of radiant flux, $\lambda$ is a wavelength of radiation in the PAR range, $h-$ Planck constant, $c$-velocity of light, $N_{A}$-Avogadro number.

The expression for $E_{P P F D}$ can be written accordingly.

Despite the simple form of a linear function $S(\lambda)$, there are serious metrological challenges associated with measurements of photosynthetic photon values, which warrants a separate discussion.

There are several foreign and locally produced devices $[39,40]$ for spectral and integral measurements of $\Phi_{P P F}$ and $E_{P P F D}$ in Russia. However, none of them is included in the State Register of measuring instruments, since they do not guarantee accu- rate measurements except for the most simple case, i.e. for an HPS irradiator.

\subsection{Norms and recommendations for greenhouse lighting}

Development of lighting technology, and the emergence of LED-irradiators increased the importance of creating a regulatory basis for greenhouse lighting. Very little is available now; the only document of an advisory nature describes the problems of greenhouse lighting incorrectly [41].

In 2016 in VNISI, two standards were developed [42-45] related to the regulation and control of the photosynthetic photon flux in production of LED-irradiators and measurements of photosynthetic photon flux density in greenhouses, where in fact a new system of photosynthetic photon quantities was introduced for the first time.

The regulations for greenhouse lighting are being actively developed abroad as well. In July 2017 the United States issued the national standard "Quantities and units of optical radiation for plants". The standard was prepared with the participation of an international group of experts from the American national standards Institute (ANSI) and the American society of agricultural and bio-engineers $(A S A B E)$ [46]. Several other standards on lighting in greenhouses [47] are under preparation in the United States. We hope similar work will begin in Russia as well.

To conclude this review of what appear to be quite different lighting systems, we would like to note one important general fact: agricultur- 
al lighting in Russia, which only 15-20 years ago was based on outdated luminaires and lighting sources (incandescent lamps, T12 fluorescent lamps, high-pressure mercury lamps), has made a significant leap forward and by using the latest lighting technologies is making a significant contribution to the import substitution drive and supplying the population with high-quality food products.

\section{REFERENCES}

1. OSN-APK 2.10.24.001-04 Lighting norms for agricultural enterprises, buildings and constructions. Moscow, 2004.

2. Kansvol N. More light in the barn // New agriculture. Moscow, 2006, № 1, pp. 58-62.

3. Kansvol N., Mathias S. FürmehrlichtinsMelkstandsorgon. // Fortschritliche Landwist, 2013, № 4, pp. 14-15.

4. https://ltcompany.com/ru/products/types/ industrial-luminaires/up-to-5-meters/inox-led/ inox-led-70-ovp-5000k/.

5. http://varton.ru/products/product/158/.

6. http://www.agroinvestor.ru/companies/ article/12053-pyat-novykh-ferm-za-vosem-let/.

7. http://www.bashinform.ru/news/731905/.

8. https://agrobelarus.by/articles/nauka/ kakoy_svet_nuzhen_v_svinarnike_/.

9. Kavtarashvili A. Sh. Technology of increasing the efficiency of production of chicken eggs / Dissertation of doctor of agricultural sciences (specialty 06.02.04), Sergiyev Posad, 1999, 366 p.

10. Mukhamedina A.R. The impact of light on behaviour and productivity of birds // Veterinary, 2005, № 6, pp. 16-18.

11. https://www.hartmann-light.ru/_- kltfx.

12. http://refportal.com/news/business/spravochnik-po-ndt-v-pishievoy-promishlennosti-poyavitsya-v-217-godu/.

13. Gladin D.V. Lighting in poultry: The past and the present. http://www.ntp-ts.ru/upload/iblock/1f0/past_and_ present.pdf.

14. Ruchin A.B. Influence of photoperiod on growth, physiological and hematological indices of juvenile Siberian sturgeon // RAS news, Biological series, 6, pp. 698-704. 15. Vkasov V.A., Maslova N.I., Ponomarev S.V., Bakaneva Yu.M. The effect of light on growth and development of fish // Herald of AGTU. Series: Fish farming, 2013, № 2, pp. 24-33.

16. http://www.akvagroup.com/products/ cage-farming-aquaculture/underwater-lights.

17. http://aquafarmer.ru/.
18. http://www.akvagroup.com/news/image-gallery.

19. Grigoryev S.S., Sedova N.A. Industrial fish farming // Handbook. Kamchatka State University, Part 1, 2008, 353 p.

20. Poedinok N.L. The use of artificial light in mushroom cultivation // Biotechnology ACTA, 2013, № 6, pp. 58-70.

21. Purschwitz I., Muller S., Kasther Ch. Sealing the rainbow: light sensing in fungi. // Current Opinion in Microbiology, 2006, Vol. 9, No. 6, pp. 566-571.

22. Devochkina N.L. Intensive growing of oyster mushrooms in greenhouse // Greenhouses in Russia, 2009, № 3, pp. 23-26.

23. Glushakov O.V., Alekseeva K.L. Growing of oyster mushrooms in "Agrico Ltd.”, Chuvash Republic // Greenhouses in Russia, 2017, № 2, pp. 28-29.

24. http://gribportal.ru/vyrashchivanie/vyrashchivanie-veshenok-v-domashnih-usloviyah-dlya-novichkov/.

25. Prikupets L.B. Light culture. A rational approach to the choice of lighting system // Greenhouses in Russia, 2016, № 1, pp. 56-61.

26. http://galad.ru/catalog/? FILTER [KLASS_PROD]=1503

27. Prikupets L.B. Light culture. Lamps are operating. When shall be replaced? // Greenhouses in Russia, 2015, № 1, pp. 52-53.

28. Emelin A.A., Prikupetz L.B., Tarakanov I.G. The spectrum effect in LED irradiators for growing lettuce // Svetotekhnika, 2015, № 4, pp. 47-52.

29. Yemelin A.A., Prikupets L.B., Tarakanov I.G. Spectral Aspect when Using Light-Emitting Diode Irradiators for Salad Plant Cultivation under Photoculture Conditions // Light\& Engineering, 2015, Vol. 23, No. 4, pp. 41-45.

30. Boos G.V., Prikupets L.B., Terehov V.G. Tarakanov I.G. Studies in the field of plant irradiation with LEDs //The $10^{\text {th }}$ Asia Lighting Conference, Shanghai, China, August 17-18, 2017, http://asialightingconference.org/index.php.

31. Prikupets L.B., Terehov V.G., Tarakanov I.G. LED and HPS luminaires in Russian greenhouses // Lux Europa 2017, Ljubljana, Slovenia, September 18-20, 2017, http://www.luxeuropa2017.eu/.

32. http://www.lighting.philips.ru/products/ horticulture.

33. http://innovatube.com/2016/12/26/ cac-cong-nghe-moi-duoc-mong-cho-nam-2017-phan-2/.

34. http://fibonacci.farm/models. 
35. Prikupets L.B., Yemelin A.A. The use of LED-irradiators for growing lettuce: economy aspect // Greenhouses in Russia, 2013, № 3, pp. 66-68.

36. https://www.vegprice.ru/news/tag/0/7965-philipslighting, application date: 05.07.2017.

37. Tooming H.G., Gulyaev B.I. Methods of measuring photosynthetic active radiation // Manual, Moscow, Nauka, 1967, 143 p.

38. Vornorm DIN5031 Teil 1 (1985) "Strahlungsphysik im optischen Bereich”.

39. Kuzmin, V.N., Nikolaev, S.E. Methods and devices for quick evaluation of efficiency of optic radiation in photoculture // Svetotekhnika, 2016, № 4, pp. 41-43.

40. Kuzmin, V.N., Nikolaev, S.E. Methods and Devices for quick evaluation of efficiency of optic radiation under Photoculture Conditions //Light \& Engineering, 2016, No. 4, pp. 99-104.

41. RD-APK 1.10.09.01-14 Methodical recommendations on design of greenhouses for cultivation of vegetables and seedlings. Moscow, 2014.
42. GOST R57671-2017 “Irradiation devices with LED light sources for greenhouses. General specifications".

43. PNST 211-2017 “The exposure of plants by LED light sources. Methods of measurements".

44. Rozovskiy E.I., Prikupets L.B., Stolyarevskaya R.I. Standardization in the field of lighting equipment and installations for greenhouses // Svetotekhnika, 2017, № 6, pp.69-74.

45. Rozovskiy E.I., Prikupets L.B., Stolyarevskaya R.I. Standardization in the field of lighting equipment and installations for greenhouses // Light\& Engineering, 2018, Vol. 26, No. 1, pp.--

46. ANSI/ASABE S640 “Quantities and Units of Electromagnetic Radiation for Plants (Photosynthetic Organisms)”.

47. Jianzhong J. Stakeholders make progress on LED lighting horticulture standards // LEDs Magazine, June, 2015, pp. 39-41.

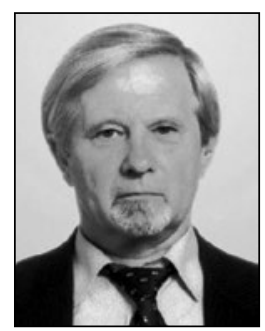

Leonid B. Prikupets,

Ph.D., graduated with honours from MPEI in 1970. At present, he is the Head of Laboratory at VNISI named after S.I. Vavilov and a lead technical consultant at LLC "BL Trade" 


\section{Leonid B. Prikupets}

\section{Technological Lighting in the Agro-Industrial Complex in Russia}
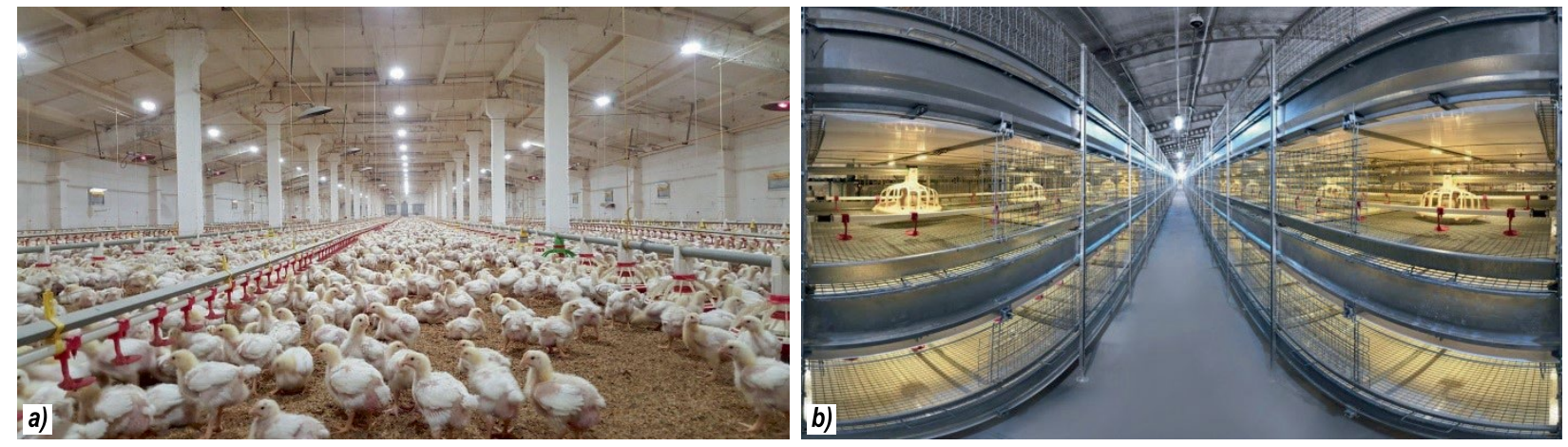

Fig. 4. LED lighting in poultry complex: a) with floor reared poultry [11]; b) with caged birds [12]
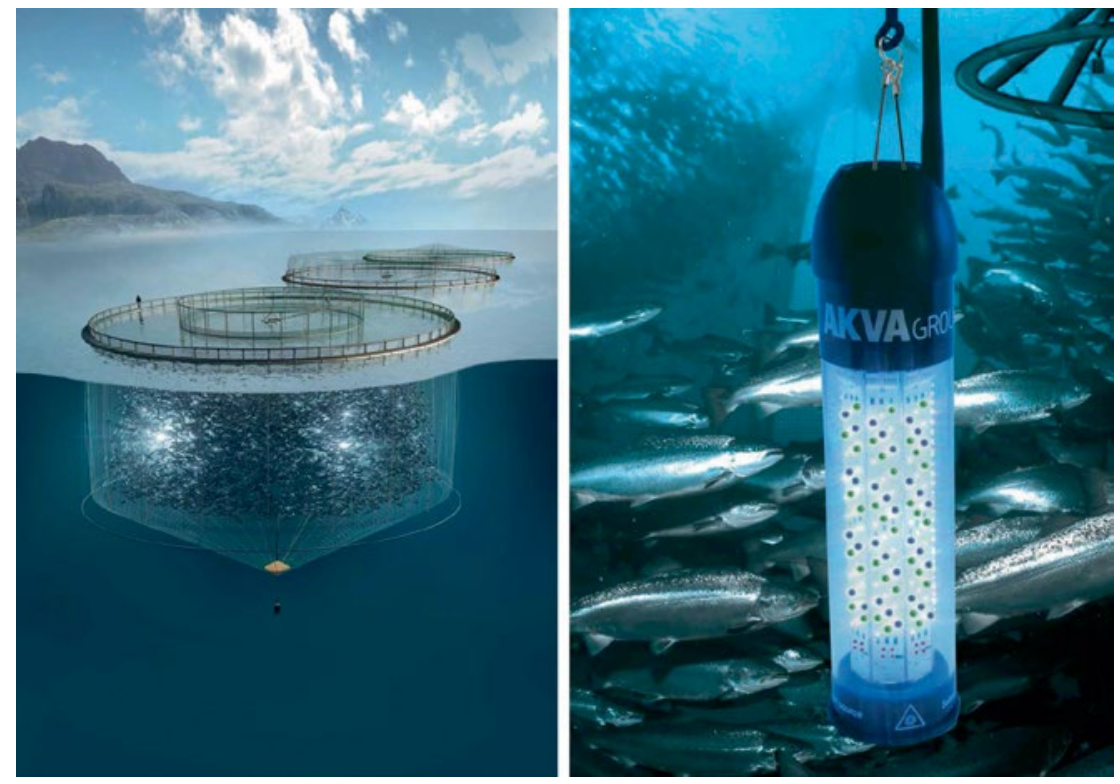

Fig. 7. Lighting in aqua farm using a submersible fixture [18]

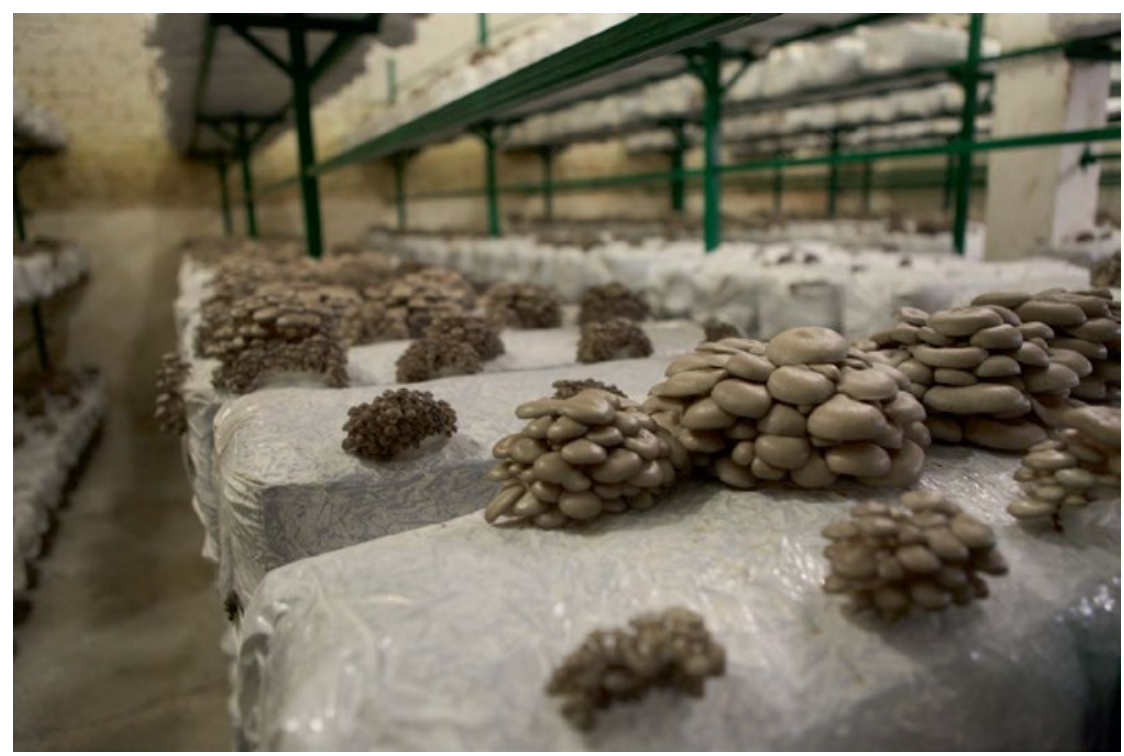

Fig. 8. Oyster mushrooms farm [24] 
Leonid B. Prikupets

Technological Lighting in the Agro-Industrial Complex in Russia

a)

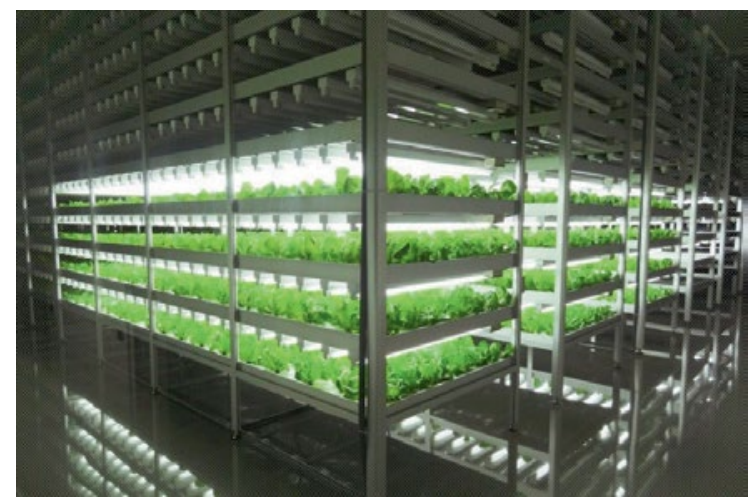

b)

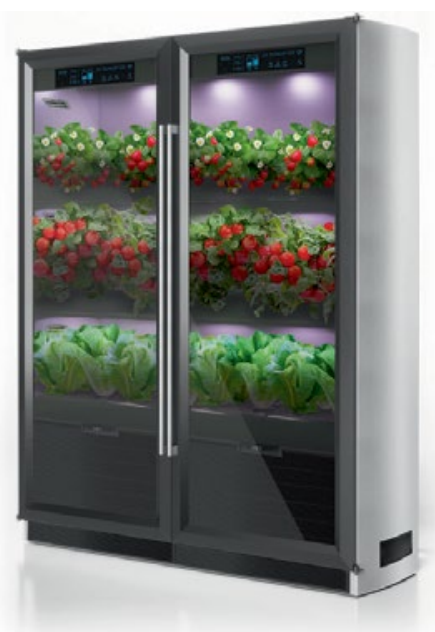

Fig. 14. Multi-stack installation for growing plants with LED irradiation: a) industrial, "CityFarm" type [33]; b) home-scale [34]

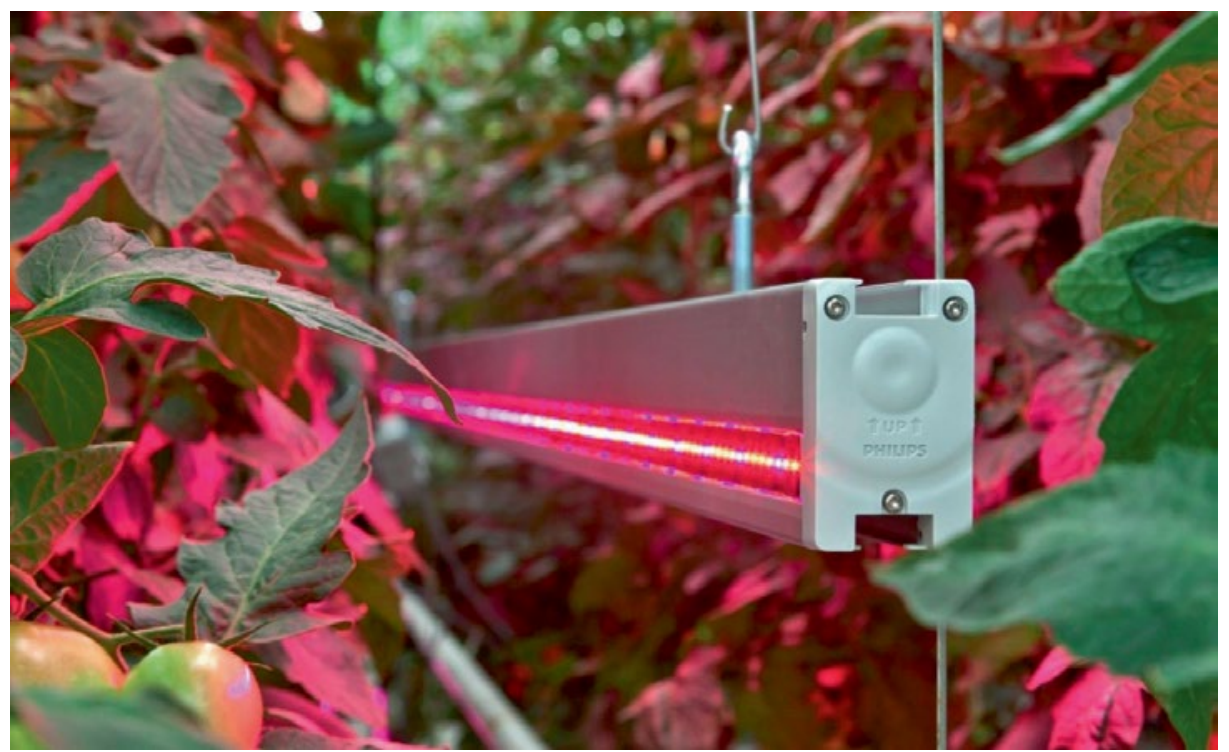

Fig. 13. Inter-row lighting system with Philips LED-irradiators [32] 